\title{
Una visión sinóptica de Auguste Comte en inglés
}

\author{
A synoptic view of Auguste Comte in English \\ Tonatiuh Useche Sandoval ${ }^{i}$ \\ ' Doctor en Filosofia, Université Paris 1 - Panthéon-Sorbonne. \\ Paris - France \\ orcid.org/0000-0002-1359-2290 \\ Tonatiuh.Useche@ac-paris.fr
}

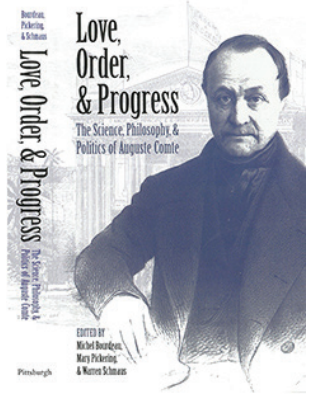

BOURDEAU, Michel; PICKERING, Mary; SCHMAUS, Warren (Ed.). Love, order, and progress: the science, philosophy, and politics of Auguste Comte. Pittsburgh: University of Pittsburgh Press. 2018. 416p.
En el Capítulo 86 de Rayuela de Julio Cortázar (2008) se puede leer: "Quizá haya un lugar en el hombre desde donde pueda percibirse la realidad entera. Esta hipótesis parece delirante. Auguste Comte declaraba que jamás se conocería la composición química de una estrella. Al año siguiente, Bunsen inventaba el espectroscopio". Nada se aleja tanto de la estructura fragmentada de la novela de Cortázar como la obra sistemática del fundador de la religión de la humanidad. El presente volumen reúne nueve artículos en inglés que, descartando una comprensión fragmentaria de la obra de Comte, tanto de sus aciertos como de sus insuficiencias, resaltan que sus vertientes científica, filosófica y política son solidarias.

La primera parte inicia con un artículo de Warren Schmaus quien subraya que la pregunta formulada por Comte era: ¿cómo sacar conclusiones normativas sobre los métodos científicos a partir de una descripción del pasado? Comte muestra así que el saber científico es un producto histórico, por lo cual su evaluación depende del momento que atraviesa la sociedad y del grado de interacción entre

las comunidades científicas. Conformemente a la epistemología positivista, el siguiente artículo de Michel Blay destaca que Comte comprende las matemáticas de una manera que refleja un momento en el desarrollo de la física tal y como era practicada por los ingenieros egresados de la École Polytechnique en donde Comte recibió una parte de su formación académica. Luego, Anastasios Brenner recuerda que Comte dictó un curso gratuito de astronomía popular entre 1832 y 1849, para probar que una ciencia que se ocupa de objetos remotos podía acarrear la decadencia social de las cosmologías teológicas.

Laurent Clauzade presenta luego a Comte como un filósofo de la biología porque libró esta ciencia del espíritu metafísico del vitalismo para constituirla como una disciplina autónoma. Pero, por otra parte, Comte elaboró una ciencia biológica incompleta y 
subordinada a la sociología. En efecto, la tarea de estudiar el organismo más complejo, es decir la humanidad, queda en manos de la sociología, mientras que el oficio de estudiar el órgano más complicado, o sea el cerebro humano, le compete a la séptima ciencia: la moral. Vincent Guillin rescata, a continuación, tres características mayores de la sociología positivista. Primero está la importancia capital atribuida a la inteligencia. Segundo, la sociología positivista emerge como resultado de un contexto epistemológico, lo cual se expresa en la ley de clasificación de las (seis principales) ciencias. Tercero, la sociología excluye la sicología y la economía política de la escala del saber enciclopédico por promover una visión atomística del ser humano.

Ya en la segunda parte del volumen, Michel Bourdeau recalca que esta crítica del individualismo es inseparable de un rechazo al comunismo por su tendencia a suprimir la individualidad. Comte observa que existe una modificabilidad natural y que los organismos sociales tienden hacia una especialización indispensable, aunque finalmente nociva. De ahí, dos aforismos característicos de la política positiva: "no hay sociedad sin gobierno" y "ninguna sociedad puede conservarse sin un poder espiritual cualquiera" o, mejor dicho, sin un poder moderador. Pero interpretar el poder espiritual como un proyecto totalitario sería una injusticia: los seguidores de la política positiva nunca justificaron ideologías criminales como el racismo, el nacionalismo o el colonialismo. Jean Elisabeth Pedersen, en el Capítulo 7, destaca que Comte contrastaba la racionalidad masculina con la afectividad femenina. Este contraste no servía para enaltecer la función biológica de la madre, sino la función social de la mujer como educadora de la infancia, moderadora de la opinión pública y emblema espontáneo de la humanidad. Esta superioridad secundaria de las mujeres en lo emocional, se combina con una inferioridad fundamental frente al género masculino en las triples relaciones de fuerza física, intelectual o anímica. Andrew Wernick sostiene, para terminar, que considerar la obra de Comte desde la perspectiva exclusiva de la filosofía de la ciencia es un desacierto: Comte es menos el heraldo de la tecnocracia política que un pensador de la cuestión religiosa. La religión positiva es más que un catolicismo descristianizado, es una síntesis que acoge componentes del fetichismo y del islam, así como la adoración china del cielo y de la tierra.

En la conclusión del volumen, Mary Pickering recuerda que cuando Comte falleció en 1857, la sociedad positivista contaba con 37 discípulos. Sin embargo, el positivismo caló hondo en territorios por fuera de Europa y de los EEUU, a despecho que se trataba de regiones que no estaban industrializadas. De India a Brasil, la ley de los tres estadios brindó a intelectuales, que salían de la clase media, una explicación histórica del atraso de sus países, así como la posibilidad de cambiar la realidad social sin admitir ninguna inferioridad respecto a Occidente y sin sacrificar sus tradiciones ni recursos. En efecto, el positivismo fue una de las pocas doctrinas anti-imperialistas y anti-colonialistas que surgieron en la Europa del siglo XIX.

En suma, cada ensayo reafirma la idea de que la obra de Comte y sus seguidores sigue siendo capaz de deslumbrarnos. ¿Acaso no es deslumbrante que Comte concibiera la creación de la Revue Occidentale en 1852, que sus discípulos publicaran una revista bajo este nombre entre 1878 y 1914, y que, en 1923, Ortega y Gasset fundara la Revista de Occidente? Emana de este volumen, como del último libro de Annie Petit (2017), un clamor para que 
una nueva generación de académicos echen una mirada cautelosa a la filosofía y política positivas, y que se exploren los numerosos archivos que la actual reorganización de La Maison d'Auguste Comte, radicada en París, ha devuelto a la luz del día.

\section{REFERENCIAS}

BOURDEAU, Michel; PICKERING Mary; SCHMAUS Warren (Ed.).

Love, order, and progress: the science, philosophy, and politics of Auguste Comte. Pittsburgh: University of Pittsburgh Press. 2018.
CORTÁZAR, Julio.

Rayuela. Madrid: Cátedra. 2008.

PETIT, Annie.

Le système d'Auguste Comte. Paris: Vrin. 2017.

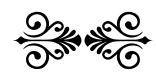

